\title{
Article
}

\section{Vaccination policy in Italy: An update}

\author{
Stefano Crenna, Antonio Osculati, Silvia D. Visonà \\ Section of Legal Medicine and Forensic Science, Department of Public Health, Experimental and Forensic \\ Medicine, University of Pavia, Italy
}

\begin{abstract}
Significance for public health
Immunization is widely considered to be one of the greatest achievements of public health policies. The effective control of vaccine-preventable diseases generally requires indefinite maintenance of extremely high rates of timely vaccination. However, vaccines represent one of the most important aspects of pediatric preventive care, as they represent an essential tool to prevent illness and save lives. Yet, the success of this fundamental public health measure is directly dependent on parental compliance, which must be increased using evidence-based communication strategies to address vaccine hesitancy. Therefore, vaccine hesitancy is an extremely important issue that needs to be urgently addressed. In Italy, concerns about vaccine safety have led a worrying number of families to decline the recommended vaccination plans for their children. This alarming tendency is, currently, leading to a resurgence of some diseases and, in addition, to the actual risk of outbreaks. Regional laws generated a growing inhomogeneity, starting from 2005, causing an alarming drop of immunization rate, being currently $85 \%$, one of the lowest in Europe.
\end{abstract}

\section{Vaccination policy}

Immunization is widely considered to be one of the greatest achievements of public health policies.

Yet, in Italy, concerns about vaccine safety have led a worrying number of families to decline the recommended vaccination plans for their children. This alarming tendency is, currently, leading to a resurgence of some diseases and, in addition, to the actual risk of outbreaks. As already pointed out by some American authors, vaccine refusal has been associated with outbreaks of invasive Haemophilus influenzae type b disease, varicella, pneumococcal disease, measles, and pertussis, resulting in the unnecessary suffering of young children and waste of limited public health resources. ${ }^{1}$

Most of those concerns are based on the fear of life-threatening side effects. Indeed, it is well known that vaccines can actually cause some adverse effects, even serious ones, but they are extremely rare, especially if compared to the benefits that vaccines provide (Table 1).

In 1998, Wakefield et al. published an article in which a possible relationship between measles/mumps/rubella vaccine and autism was hypothesized. ${ }^{2}$ Many studies since then showed no causal relation between measles/mumps/rubella vaccine and autism. ${ }^{3-6}$ Yet, the controversy lead to a diffuse confusion, especially among children's parents, about this issue. Then, in 2004, ten of the authors of the Lancet study formally retracted their support for the published hypothesis. Finally, the Lancet withdrew the article in $2010 .{ }^{7}$ Moreover, in literature there is strong scientific evidence that childhood vaccines are not associated with autism or leukemia: for instance, a systematic literature, published by Maglione et al. in 2014, examined 67 studies, finding that measles/mumps/ rubella vaccine is not associated with autism (Table 1)..$^{8,9}$

In fact, in most well-developed countries, the high rate of childhood vaccination coverage indicates that immunization programs remain a generally accepted and diffuse public health measure. It is interesting to notice that Italy is one of the few countries in which vaccines are mandatory by law. This fact appears to be in contrast with the ongoing tendency not to vaccinate children, endorsed mostly by misinformation provided by social media and blogs.

Nonetheless, as often happens in Italy, the regulations about this delicate topic are controversial and, to some extent, inconsistent. The recent Italian Decree Law n. 73/2017, that we are going to illustrate below, is only the "icing on the cake", a very complex cake, made of many layers. In the following pages, we are going to provide an overview of a situation that other authors have already defined, very pertinently, as an oxymoron. ${ }^{10}$ In fact, vaccines in Italy are compulsory by law since the 30 s (diphtheria), and the 60s (anti-tetanus, anti-poliomyelitis). Notwithstanding, regional laws generated a growing inhomogeneity, starting from 
Veneto in 2008, causing an alarming drop of immunization rate, being currently $85 \%$, one of the lowest in Europe. 10 Note that a $93-95 \%$ coverage is required to grant herd immunity.

As stated by art. 32 of the Italian Constitution: The Republic safeguards health as a fundamental right of the individual and as a collective interest, and guarantees free medical care to the indigent. No one may be obliged to undergo any given health treatment except under the provisions of the law. The law cannot under any circumstances violate the limits imposed by respect for the human person. It is important to note that health (both individual and collective) is not the only right safeguarded by this article. The Italian Supreme Court repeatedly stated that the right to health must be distinguished from the right to self-determination, the latter being a form of respect for personal freedom and a mean to pursue an individual's best interest $\mathrm{s}^{\mathrm{i}}$ and originating from both art. 32 and art. 13 of the Italian Constitution: Personal liberty is inviolable. No form of detention, inspection or personal search nor any other restriction on personal freedom is admitted, except by a reasoned warrant issued by a judicial authority, and only in the cases and the manner provided for by law. In exceptional cases of necessity and urgency, strictly defined by the law, law-enforcement authorities may adopt temporary measures that must be communicated to the judicial authorities within forty-eight hours. Should such measures not be confirmed by the judicial authorities within the next forty-eight hours, they are revoked and become null and void. All acts of physical or moral violence against individuals subject in any way to limitations of freedom shall be punished. The law establishes the maximum period of preventive detention. ${ }^{11}$

As stated by the Italian Constitutional Court, informed consent must be considered as a fundamental principle when dealing with health protection, and its translation into reality is determined by State laws. ${ }^{\text {ii }}$

Table 1. Comparison between disease-related risks and vaccine-related risks.

\begin{tabular}{|c|c|c|}
\hline Disease & Disease-related risks & Vaccine-related risks \\
\hline $\begin{array}{l}\text { Measles } \\
\text { Mumps } \\
\text { Rubella }\end{array}$ & $\begin{array}{l}\text { Pneumonia: } 1 / 20 \text {; Encephalitis: } 1 / 2000 \text {; Death: } 1 / 3,000 \\
\text { Encephalitis: } 1 / 300 \\
\text { Congenital rubella: } 1 / 4 \text { if contracted at the beginning of pregnancy }\end{array}$ & Encephalitis or severe allergic reactions: $1 / 1,000,000$ \\
\hline $\begin{array}{l}\text { Diphtheria } \\
\text { Tetanus } \\
\text { Pertussis }\end{array}$ & $\begin{array}{l}\text { Death: } 1 / 20 \\
\text { Death: } 3 / 100 \\
\text { Pneumonia: 1/8; Encephalitis: 1/20; Death: 1/20 }\end{array}$ & $\begin{array}{l}\text { Inconsolable crying followed by complete recovery: } 1 / 100 ; \\
\text { Convulsions or shock followed by complete recovery: } 1 / 1750 \text {; } \\
\text { Acute encephalopathy: } 0-10.5 / 1,000,000 \text {; Death: unproven }\end{array}$ \\
\hline Varicella & $\begin{array}{l}\text { Incidence: } 4000 / 100,000 \text {; Lethality: 4-9/100,000; } \\
\text { Hospitalization: 1,3-4,5/100,000; Neurological complications: } \\
\text { 0.4-10.1\% of hospitalized patients; Pneumonia: 5-14\%; } \\
\text { Skin superinfections: } 36 \% \text { of hospitalized patients }\end{array}$ & $\begin{array}{l}\text { Varicella-like rash: 3.8\%; Pneumonia: }<1 \% \text {; Febrile } \\
\text { convulsions: }<0.1 \% \text {; Severe allergic reactions: }<0.01 \%\end{array}$ \\
\hline Meningococcal meningitis & $\begin{array}{l}\text { Lethality: 10\%; Complications: } 25 \% \text { (amputations, } \\
\text { skin lesions, hemiplegia, mental retard, epilepsy, } \\
\text { neurological deafness, post-traumatic stress disorder, } \\
\text { depression, anxiety) }\end{array}$ & $\begin{array}{l}\text { Dizziness: }<1 / 100 \text {; Paresthesia, anaphylactic reactions: } \\
<1 / 10,000\end{array}$ \\
\hline $\begin{array}{l}\text { Invasive pneumococcal } \\
\text { disease (IPD) }\end{array}$ & $\begin{array}{l}\text { Lethality: } 15-20 \% \text { in case of pneumococcal sepsis in adults, } \\
30-40 \% \text { in case of pneumococcal sepsis in people over } 65 \text {, } \\
12 \% \text { in case of pneumococcal meningitis } 12 \% \text {. } \\
\text { Neurological sequelae: } 40 \% \text { of pneumococcal } \\
\text { meningitis survivors }\end{array}$ & $\begin{array}{l}\text { Hypersensitivity reactions including facial edema, } \\
\text { dyspnea, bronchospasm, convulsions } \\
\text { (including febrile convulsions), rash, urticaria or } \\
\text { urticaria rash, anaphylactic reactions, angioedema, } \\
\text { hyporesponsive-hypotonic episodes, urticaria on }\end{array}$ \\
\hline $\begin{array}{l}\text { Non-invasive } \\
\text { pneumococcal disease }\end{array}$ & $\begin{array}{l}\text { CAP mortality: } 5-15 \% \text { in hospitalized patients, } \\
20-45 \% \text { in ICU patients, } 40 \% \text { in people over } 80\end{array}$ & $\begin{array}{l}\text { the site of injection, itching on the site of injection, } \\
\text { hot flushes, apnea in very premature newborns: } \\
<1 / 1,000 \text {. Lymphadenopathy (near the site of } \\
\text { injection), erythema multiforme: }<1 / 10,000\end{array}$ \\
\hline $\begin{array}{l}\text { Haemophilus Influenzae } \\
\text { infection (HiB) }\end{array}$ & $\begin{array}{l}\text { Lethality: } 3-6 \% \text {. Complications: } 20 \% \text { of patients who } \\
\text { survive the Hib meningitis report hearing loss and other } \\
\text { neurological sequelae. }\end{array}$ & $\begin{array}{l}\text { Allergic reactions, angioedema, hypotonic-hyporesponsive } \\
\text { episodes, convulsions, syncope or vasovagal reactions } \\
\text { during injection, drowsiness, apnea, urticaria, rash, } \\
\text { extensive swelling of the injected limb, hardening } \\
\text { of the site of injection }\end{array}$ \\
\hline Poliomyelitis & $\begin{array}{l}\text { Fever, weakness, headache, nausea, flu-like syndrome, } \\
\text { nuchal/spinal rigidity, pain in the limbs: } 4-8 \% \text {. } \\
\text { Permanent paralysis: } 1 \% \text {. Mortality: } 5-15 \% \text { of cases } \\
\text { of acute paralytic poliomyelitis }\end{array}$ & $\begin{array}{l}\text { Local reactions on the injection site (pain, redness, } \\
\text { hardening, edema): } \geq 1 / 10\end{array}$ \\
\hline Hepatitis B & $\begin{array}{l}\text { Mortality due to acute hepatitis: } 2 \% \\
\text { Development of a chronic infection: } \\
>30 \% \text { in children, }<5 \% \text { in adults } \\
\text { Complications of chronic infections: } \\
\text { liver cirrhosis } 25 \% \text {, liver cancer } 5 \%\end{array}$ & $\begin{array}{l}\text { Lymphadenopathy, arthralgia, paresthesia, hives, itching and } \\
\text { rash: <1/1000. } \\
\text { Thrombocytopenia, encephalitis, encephalopathy, } \\
\text { convulsions, paralysis, neuritis, neuropathy, hypoaesthesia, } \\
\text { apnea in very premature newborns very premature, } \\
\text { erythema multiforme, angioneurotic oedema, lichen planus, } \\
\text { arthritis, muscle weakness, meningitis, vasculitis, } \\
\text { hypotension, anaphylaxis, allergic reactions including } \\
\text { anaphylactoid reactions and serum sickness-like reaction. }\end{array}$ \\
\hline
\end{tabular}


Lawmakers have always been trying to balance out the individual's rights to health and self-determination and the right of the collectivity to health by allowing a limited number of compulsory health treatments and medical examinations. The most popular form of compulsory treatment is the forced psychiatric hold, originally regulated by the so-called "Basaglia Act" (Italian law n. $180 / 1978$ ), which was soon transposed into the "Italian National Health Service Institution Act" (Italian law n. 833/1978).

Mandatory vaccinations are another form of unintentional treatments, often performed on children. Based on Italian law, people gain their contractual and mental capacity when turning eighteen years old (as stated by art. 2 of the Italian Civil Code and arts. 85,97 and 98 of the Italian Penal Code). Therefore, only adults can fully defend their rights to health and self-determination, and procedures on minors must usually be endorsed by his/her parents or legal guardian(s).

However, when dealing with a minor's health, it is essential to keep in mind that he/she must be "protected from parents not fulfilling their duty of care", ${ }^{i i i}$ as required by arts. 30 and 31 of the Italian Constitution.

Indeed, "in the case of a minor, we are not dealing with his/her self-determination, but with his/her parents' authority and duty to act to avoid damages or actual dangers to his/her health, and we cannot grant parents a full freedom to make potentially harmful decisions". iv

In a period of worrying tendency to decline vaccinations due to the parents' skepticism about pharmaceutical companies and health policies, the Italian government has justifiably decided to deploy an emergency ordinance.

However, we would like to remind that, even before the Italian Decree Law n. 73/2017 was approved, mandatory vaccinations for children included all of the following: anti-diphtheria (Italian Law n. 891/1939), anti-tetanus (Italian Law n. 292/1963), antipoliomyelitic (Italian Law n.51/1966) and anti-hepatitic B (Italian Law n. 165/1991). In the event of non-compliance, administrative sanctions (ranging from 10 to 258 euros) were imposed (there was no specific sanction for the omission of the diphtheria vaccination, which was however generally administered in association with the anti-tetanus vaccination).

The above-mentioned regulations, and their subsequent amendments and additions, provided that the vaccination certificates had to be presented to primary schools to complete enrollment. Furthermore, for about thirty years (from the late 1960s to the late 1990s), "school directors and heads of public or private educational institutions" could not admit to school or exams the ones who did not prove, "with the presentation of a certificate issued under the law, to have been subjected to mandatory vaccinations and revaccinations".. Following the approval of the Presidential Decree n. 355/1999, this provision was renewed as follows: "In the case of non-submission of the certification or declaration ..., the school director or the head of the institution communicates the fact within five days, for the opportune and timely interventions, to the unit company local health of the pupil and the Ministry of Health. Failure to certify does not imply the refusal of the pupil's admission to compulsory schooling or exams". Health authorities (mayors, Regions or State) still maintained the right to take urgent action in the event of health emergencies or public hygiene, based on art. 117 of the Italian Legislative Decree n. 112/1998.

The limited deterrent effectiveness of the already mentioned sanctioning system, and the changes introduced by the Italian
Constitutional Law n. 3/2001 (devolution of almost all the competences and responsibilities in health matters to the Regions and the Autonomous Provinces), were the fertile ground in which new vaccine policies were generated and developed, radically different from the existing ones: many Regions, based on what was decided in 2005 - on an experimental basis - by the State-Regions Conference, decided to abolish the vaccination obligation and/or to stop the imposition of administrative sanctions on non-compliant parents.

At the same time, however, there was a tendency to offer actively and freely, especially for the newborns' cohorts, some further vaccinations, called "recommended" and included in the vaccination timetables (see Italian National Health Plan 1996-1998, Italian National Plan for Vaccines 1999-2000, New Italian National Plan for Vaccines 2005-2007, Italian National Plans for Vaccine Prevention 2012-2014 and 2017-2019): measles, mumps, rubella, pertussis, Haemophilus influenzae type b, meningococcus B and $\mathrm{C}$, pneumococcus, varicella, HPV, rotavirus. It should also be noted that vaccinations have been included in the LEA ("Livelli Essenziali di Assistenza", fundamental assistance standards) since 2002 (see Decree of the President of the Council of Ministers 29th November 2001).

Meanwhile, jurisprudence had also dealt with the subject of the indemnity of the (rare, but possible) damages consequent to mandatory health treatments. Following the Italian Constitutional Court's pronunciation n. 307/1990 (which had declared "the constitutional illegitimacy of the law of February 4, 1966, No. 51 (Obligation of the anti-poliomyelitic vaccination) in the part in which it does not provide, by the State, a fair indemnity for the case of damage deriving ... from infection or other appreciable disease causally due to the compulsory anti-poliomyelitic vaccination, reported by the vaccinated child or other subject due to direct personal assistance given to the first"), Italian Law n. 210/1992 was approved. It is still in force, and imposes a "Compensation in favor of those injured by irreversible complications due to mandatory vaccinations, transfusions and administration of blood products". Subsequent legislative measures (see Italian Law n. 641/1996) and sentences of the Italian Constitutional Court (see judgments $n$. 118/1996, 27/1998, 423/2000 and 107/2012) have since then expanded both the amount of the economic benefits, and the number of beneficiaries, providing for the indemnity payment to people who had suffered a permanent impairment of the psycho-physical integrity following the administration of only "recommended" vaccines. ${ }^{12}$ Italian Law n. 229/2005, containing "Provisions on compensation in favor of persons damaged by irreversible complications due to compulsory vaccinations", established the provision of further compensation to the injured parties (and/or their relatives), in the form of a monthly check.

This complex regulatory framework generated great confusion and a diffuse mistrust: vaccinations were no longer compulsory; in some cases, they seemed to have been even harmful; at the same time, more than ten vaccinations were offered free of charge. Many people started to promote doubts about the usefulness and the real safety of vaccinations; some raised (and still raise) perplexities about the justification of the healthcare costs related to the purchase and administration of vaccines. On the other hand, as highlighted by the Italian Ministry of Health, "The vaccination coverage at 24 months from the year 2000, after an upward trend, stabilized in the middle of the next decade ... The vaccine coverage for measles and rubella, going from $90.4 \%$ (2013) to $85.3 \%$ (2015), is particu-

\footnotetext{
iiiItalian Constitutional Court, sentence n. 132/1992 
larly worrying and is cracking the international credibility of our country".vi

Even the Italian National Bioethics Committee (see the motion "The importance of vaccinations", approved on 24th April 2015) and the Italian National Federation of the Medical Councils (see the "Document on vaccines" by FNOMCeO, approved on 8th July 2016) had expressed concern in this regard.

Not without media controversy, region Emilia Romagna was the first Italian Region to establish that the fulfillment of the vaccination obligation was a necessary requirement for admission to kindergartens (see Regional Law n. 19/2016). A few months later, similar rules were also approved in other regions. On 7 th June 2017, after weeks of discussions, polemics and a tough tug of war with the Minister of Education, the well-known Italian Decree Law n. 73, containing "Urgent provisions concerning vaccination prevention" was approved: the total amount of compulsory vaccinations was brought to twelve; immunization following a natural disease involved the exoneration from the vaccination obligation; moreover, in the event of an established health hazard, in relation to specific documented clinical conditions, vaccinations could be completely omitted or delayed; the imposition of sanctions against non-compliant parents (or guardians) and the prohibition of enrolling unvaccinated minors to nursery schools and kindergartens were restored; finally, it was envisaged that local health authorities would report the non-fulfillment of the vaccination obligation to the Public Prosecutor's Office at the Juvenile Court.

The text of the law, as peremptory as poor in pragmatism, was profoundly innovated by the conversion law n. 119/2017, still in force:

- at present, mandatory vaccinations (including unaccompanied foreign minors) are ten (anti-poliomyelitic, anti-diphtheria, anti-tetanic, anti-pertussis, anti-hepatitis B, anti-Haemophilus influenzae type b, anti-measles, anti-mumps, anti-rubella and anti-varicella), according to the specific indications of the national vaccination timetable for each birth cohort;

- "in case of established health hazard, in relation to specific documented clinical conditions, attested by the general practitioner or the pediatrician of free choice", the administration can be omitted or deferred; these students "are usually included in classes in which only vaccinated or immunized minors are present"; school managers must inform the local health authority of the classes in which more than two unvaccinated minors are present;

- "The immunization following a natural disease, proven by the notification made by the attending physician, according to article 1 of the Health Ministry's decree 15th December 1990 [notification, by the doctor, of all cases of diffuse diseases dangerous for public health], or from the results of serological analysis, exonerates from the obligation of the relative vaccination";

- the subject already immunized against a single pathology fulfills the vaccination obligation "as a rule and in any case within the limits of the National Health Service, with vaccines in single or combined formulation in which there is no antigen for the infectious disease for which there is immunization";

- three years after the entry into force of the law and then every three years, the Minister of Health, on the basis of "verification of epidemiological data, any adverse reactions reported in implementation of the current provisions of law and vaccination coverage reached as well as eventual reported adverse events", may suspend the obligation to vaccinate minors against measles, mumps, rubella and varicella;

- the vaccinations against meningococcus B and C, pneumococcus and rotavirus are offered actively and free of charge for children between the ages of zero and sixteen, but are not compulsory;

- in the event of failure to comply with the vaccination obligation, parents, guardians or recipients are first of all "summoned by the local health authority for an interview in order to provide further information on vaccinations and to request that they be carried out";

- the persistent failure to comply with the legal obligation determines the imposition of an administrative fine of an amount varying from 100 to 500 euros, unless the parents, guardians or trustees provide, "within the period indicated in the act of contestation, to have administered to the minor the vaccine or the first dose of the vaccination cycle, provided that the completion of the cycle foreseen for each compulsory vaccination takes place in compliance with the timing established by the vaccination schedule in relation to age";

- there is no provision for the reporting of non-compliant parents/guardians to the Public Prosecutor's Office;

- failure to comply with vaccination obligations prevents access to educational services for children and pre-schools, but not to other levels of education, nor to regional vocational training centers

As recently mentioned by the Constitutional Court ${ }^{\mathrm{vii}}$, the Italian Law Decree n. 73/2017 is, therefore, the inevitable consequence of a context that is considerably different from that in force until the early nineties: the changed socio-cultural structure required a rapid and peremptory legislative intervention. "Undoubtedly, the legal bond became more stringent: what was previously recommended, today has become mandatory", but in the medical field "recommending and prescribing are actions perceived as equally necessary in view of a specific objective". There are two elements, introduced by the conversion law n. 119/2017, which were particularly appreciated by the Italian Constitutional Court: on one hand, the establishment of a preliminary interview with non-compliant parents/guardians/carers, "an instrument particularly favorable to mutual understanding, persuasion and conscious adherence"; on the other hand, the provision of a future revision of the vaccination obligations, which allows a "valorisation of the evolutionary dynamics typical of medical-scientific knowledge", on which the choices of health policy should always be based.

In conclusion, vaccine hesitancy is an extremely important issue that needs to be addressed because the effective control of vaccine-preventable diseases generally requires indefinite maintenance of extremely high rates of timely vaccination.

Therefore, especially given the growing hesitancy to vaccinate children, a broad range of measures are required, on many levels: individual's, health system managers', physicians'. These measures do not only include new (and better) laws, but also individually tailored messages to parents who have vaccine concerns, especially first-time pregnant women. However, vaccines represent one of the most important aspects of pediatric preventive care, as they represent an essential tool to prevent illness and save lives. Yet, the success of this fundamental public health measure is directly dependent on parental compliance, which must be increased using evidence-based communication strategies to address vaccine hesitancy.

\footnotetext{
vi Italian National Plan for Vaccine Prevention 2017-2019, page 25

vii Italian Constitutional Court, sentence n. 5/2018
} 
Correspondence: Silvia D. Visonà, Section of Legal Medicine and Forensic Sciences, University of Pavia, Via Forlanini 12, 27100 Pavia, Italy.

Tel.: +39.320.6056485 - Fax: +39.0382 .520025 .

Email: silviadamiana.visona01@universitadipavia.it

Key words: Vaccines, children immunization, vaccines refusal

Contributions: SC: data collecting, manuscript writing; A0: manuscript reviewing; SDV: manuscript writing and references search.

Conflict of interest: the authors declare no potential conflict of interests.

Funding: none.

Received for publication: 22 November 2018.

Revision received: 4 December 2018.

Accepted for publication: 4 December 2018.

(C) Copyright S. Crenna et al., 2018

Licensee PAGEPress, Italy

Journal of Public Health Research 2018;7:1523

doi:10.4081/jphr.2018.1523

This work is licensed under a Creative Commons Attribution NonCommercial 4.0 License (CC BY-NC 4.0).

\section{References}

1. Salmon DA, Dudley MZ, Glanz JM, Omer SB. Vaccine hesitancy: Causes, consequences, and a call to action. Vaccine 2015;33:D66-71.

2. Wakefield AJ, Murch SH, Anthony A, et al. Ileal-lymphoid- nodular hyperplasia, non-specific colitis, and pervasive developmental disorder in children. Lancet 1998;351:637-41.

3. DeStefano F, Thompson WW. MMR vaccine and autism: an update of the scientific evidence. Exp Rev Vacc 2004;3:19-22.

4. Farrington CP, Miller E, Taylor B. MMR and autism: further evidence against a causal association. Vaccine 2001;19:36325 .

5. Doja A, Roberts W. Immunizations and autism: a review of the literature. Can J Neurol Sci 2006;33:341-6.

6. Ashraf H. US expert group rejects link between MMR and autism. Lancet 2001;357:1341.

7. Retraction-Ileal-lymphoid-nodular hyperplasia, non-specific colitis, and pervasive developmental disorder in children. Lancet 2010;375:445.

8. Maglione MA, Das L, Raaen L, et al. Safety of vaccines used for routine immunization of U.S. children: a systematic review. Pediatrics 2014;134:325-37.

9. Italian Ministry of Health. Piano Nazionale Prevenzione Vaccinale. 2016.

10. Perciaccante A, Coralli A, Bianucci R. Vaccines: The oxymoron of Italian health policy. Vaccine 2018 Available from: http://dx.doi.org/10.1016/j.vaccine.2018.10.038

11. Marchese A. Vaccinazioni obbligatorie e diritto alla salute: la "profilassi imposta" fra tensioni etiche e giuridiche. Riv Ital Med Leg 2017:1333-48.

12. Parziale A. Danno da vaccinazione e incertezza del nesso causale: il ruolo della prova per presunzioni. Riv Ital Med Leg 2017:1067-83. 